\title{
A Systematic Review of Studies on Classroom Management from 1980 to 2019
}

\author{
Kıvanç Bozkuşa
}

\author{
Received \\ Revised \\ Accepted \\ 24 November 2020 \\ 1 January 2021 \\ $\mathrm{DOI}$ \\ 25 February 2021 \\ $10.26822 /$ iejee.2021.202 \\ KIvanç Bozkuş, Educational Sciences, Artvin \\ Coruh University, Artvin, Turkey \\ E-mail:kbozkus@gmail.com \\ ORCID: https://orcid.org/0000-0002-4787-3664
}

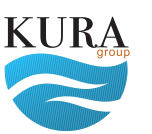

Copyright $@$

www.iejee.com

ISSN: 1307-9298

\begin{abstract}
This review study aims to reveal trends in classroom management research by employing a two-stage analysis of articles indexed by the Web of Science. The bibliometric analysis results indicated the descriptive statistics of the articles, the most productive countries and authors, the most popular articles, journals, and keywords, annual scientific production, growth of the top three journals by year, and the pioneer and influencer researchers in classroom management. The content analysis results showed the changes in the selection of methods, purposes, and participants for nearly three decades of classroom management research. This review concluded that interest in classroom management has been constantly growing, but research on classroom management is not prevalent worldwide.
\end{abstract}

\section{Keywords:}

Bibliometric Analysis, Classroom Management, Content Analysis, Systematic Review

\section{Introduction}

T eachers' classroom management skills are considered one of the most important elements that teachers should have to create effective education and training environment. Classroom management is the placement of course materials, determining the courses' duration, determining the class rules, ensuring student participation, obeying the rules, and preparing academic activities (Brophy, 1996). Classroom management involves important decisions such as how and with whom students sit, how to set the hours of the lessons, how to organize the materials, and how to ensure the participation of each student. Classroom management requires attention to ongoing events and behavioral problems in the classroom and how teachers behave and organize these teaching practices. Effective classroom management enables all students in the classroom to benefit from the teaching environment at the highest level, increase their class participation and prevent potential problem behaviors. Studies revealed that student achievement increases in an effectively managed classroom (Wilks, 1996).

The classroom environment is considered one of the main 


\section{iejee $\approx$}

places where education and training take place. There is a need for a system that will be effective in learning and teaching activities. Maintaining the order, using classroom-teaching materials effectively and efficiently, and supporting the active participation of all students in the classroom require important classroom management knowledge and skills. The main purpose of effective classroom management is to achieve the basic objectives of education by creating a positive classroom and an efficient learning environment. In this respect, classroom management aims to ensure the regular practice of class-life and self-control of all students. The key to becoming an effective teacher is to have effective classroom management. Marzano et al. (2003) highlighted that it is very difficult or even impossible for a classroom teacher who is not effective in managing the classroom, actively participating in classroom activities and using his/ her time efficiently and achieving the necessary tasks. Therefore, it can be said that in the absence of effective classroom management, students will have no active participation, and in the absence of active participation no effective learning can be achieved. Some research showed that active participation in the lesson has a very strong effect on learning (Baker et al., 2008; Greenwood et al., 2002). The research results showed that with effective classroom management, undesirable behaviors of the majority of students can be prevented, and students' participation in classes will increase (Arın et al., 2016; Soodak, 2003).A systematic review is a scientific study that examines original research on a subject through certain methods. The systematic review is the most powerful and useful source of evidence to guide implementation (Stevens, 2001). In a standard literature review, there is a possibility of researcher's bias. In systematic review, researcher's bias is prevented and minimized.

Research is evaluated according to methodological strengths and weaknesses. In a systematic review, all relevant research is sampled and evaluated. The characteristics and results of each study are summarized, digitized, coded and a database is created. The benefit of the systematic review is that it incorporates all available studies into a single report, summarizing a large amount of information and making it usable. The most important advantage of the systematic review is that it increases the power and validity of the cause-effect relationship (Stevens, 2001). Studies with the systematic review of classroom management might provide evidence-based insight into how teachers can effectively manage classrooms. However, systematic reviews of this topic are limited (Oliver et al., 2011). Although there have been attempts to review classroom management research systematically (Håkansson, 2015; Korpershoek et al., 2016; Maggin et al., 2011; Simonsen et al., 2008), these studies do not cover all types of classroom management studies. Therefore, these review studies were unable to capture all trends related to classroom management research.

Classroom management is broadly defined as everything a teacher does to create an environment for both academic and behavioral education (Evertson \& Weinstein, 2006). Research on classroom management aims to identify individual practices to support education within classrooms. These effective practices are then combined into a package for more effective education. Systematic reviews should examine classroom management as an efficient package of these practices to contribute to the existing literature. For this purpose, a more comprehensive review of existing research on classroom management should be conducted by identifying studies directly related to classroom management and published in high quality journals. Therefore, this study aims to systematically review all classroom management studies to reveal research trends over time, the most productive scholars and journals interested in classroom management, and the countries in which articles are based through a bibliometric analysis of articles indexed by the Web of Science (WoS). It is also aimed to conduct a content analysis of the articles to reveal detailed information about the methods, purposes, and participants of these studies. This systematic analysis may provide researchers with a big picture of the developments in research on classroom management.

\section{Method}

The research on classroom management was examined through bibliometric and content analysis methods. First, a bibliometric analysis draws the quantitative aspects of classroom management research by presenting the statistics related to the journals, countries, and authors. A content analysis of available full-text articles showed detailed information about the methods, purposes, and participants of these studies.

The bibliometric analysis is the application of statistical methods to published papers (Pritchard, 1969). This analysis reveals the statistics of keywords, citations, authors, sources, and countries, thus enabling researchers to explore and compare these statistics. The use of bibliometrics in educational research is new.

The rationale for selecting studies and a database is affected by the practicality of this research. As the Wos database indexes only rigorous studies from topranked journals of the world and stores many details of the papers can be analyzed through the bibliometrix (Aria \& Cuccurullo, 2017) R (Ihaka \& Gentleman, 1996) package used in this study, articles directly related to classroom management were gathered from this 
database. To determine which articles clearly focus on classroom management, the first 100 articles out of 1132 that include the term "classroom management" in the title, abstract, and keywords are carefully examined. Then the results revealed that the articles including the term in their titles are directly related to classroom management. Therefore, the database search is conducted using the title field only. The timeframe of these studies is between 1980 and 2019. Because the first study directly related to classroom management on the WoS database appears in 1980, and since it takes up to six months for the database to index all the articles in a year, studies from 2020 were excluded, and 273 studies from 1980 to until the end of 2019 were selected (Table 1). The Arts \& Humanities Citation Index, $(\mathrm{AHCl})$, Science Citation Index Expanded (SCl-Expanded), and Social Sciences Citation Index (SSCI) ) indexes on the WoS database were selected. The Emerging Sources Citation Index (ESCI) was not selected due to its lack of rigor (Bozkus, 2019).

\section{Table 1}

Number of Articles on Classroom Management Included in the Bibliometric Analysis

\begin{tabular}{lcc}
\hline Years & $f$ & $\%$ \\
\hline $1980-1984$ & 24 & 8.8 \\
$1985-1989$ & 24 & 8.8 \\
$1990-1994$ & 13 & 4.8 \\
$1995-1999$ & 18 & 6.6 \\
$2000-2004$ & 17 & 6.2 \\
$2005-2009$ & 34 & 12.5 \\
$2010-2014$ & 50 & 18.3 \\
$2015-2019$ & 93 & 34.1 \\
Total & 273 & 100 \\
\hline
\end{tabular}

For the content analysis, the full texts of the 273 articles were tried to be retrieved, but 210 full texts were available (Table 2). Most of the articles that did not have full texts were published before 1991. The analysis aimed to reveal the methods, purposes, and participants in these studies.

\section{Table 2}

Number of Articles on Classroom Management Included in the Content Analysis

\begin{tabular}{lcr}
\hline Years & $f$ & $\%$ \\
\hline $1991-1995$ & 12 & 5.7 \\
$1996-2000$ & 12 & 5.7 \\
$2001-2005$ & 15 & 7.1 \\
$2006-2010$ & 35 & 16.7 \\
$2011-2015$ & 61 & 29.0 \\
$2016-2019$ & 75 & 35.7 \\
Total & 210 & 100 \\
\hline
\end{tabular}

\section{Results}

The results of this study are presented in two sections. First, the bibliometric analysis results are elaborated using tables and figures. Then, the content analysis results are represented in a single table.

\section{Results of the Bibliometric Analysis}

The bibliometric analysis begins with descriptive statistics of the articles included in the analysis (Table 3). A total of 273 articles were published by 123 different journals from 1980 to 2019. Articles were written by 610 different authors who appeared 742 times and used 530 different keywords. Of these 610 authors, 77 of them authored their articles alone, while the remaining 533 authors had coauthors. The average number of articles per author was 0.45 , and the average number of authors per article was 2.23. Articles were cited an average of 20.15 times.

\section{Table 3}

Descriptive Statistics of the Articles Included in the Bibliometric Analysis

\begin{tabular}{lr}
\hline Description & Results \\
\hline Articles & 273 \\
Journals & 123 \\
Period & 2019 \\
Authors & 610 \\
Author appearances & 742 \\
Author's keywords & 530 \\
Authors of single-authored articles & 77 \\
Authors of multi-authored articles & 533 \\
Articles per author & 0.45 \\
Authors per article & 2.23 \\
Average citations per articles & 20.15 \\
\hline
\end{tabular}

The source countries of the articles are presented in Table 4. Most articles were written by authors from the United States of America (USA) ( $n=151)$. The other countries in the top five were Germany $(n=23)$, Turkey $(n=22)$, Netherlands $(n=9)$, and Australia $(n=9)$.

The 20 authors who published most of the articles are presented in Table 5. Carolyn M. Evertson was the author who published most articles $(n=8)$.

In terms of author scientific productivity, most of the authors $(n=494)$ published one article only (Table 6). 


\section{iejee $^{\star}$}

\section{Table 4}

The Number of Articles Per Country (Limited to the First 20)

\begin{tabular}{lrrr}
\hline Country & Articles & Country & Articles \\
\hline USA & 151 & Israel & 3 \\
Germany & 23 & Switzerland & 3 \\
Turkey & 22 & Estonia & 2 \\
Netherlands & 9 & Spain & 2 \\
Australia & 9 & Denmark & 1 \\
United Kingdom & 9 & Finland & 1 \\
Canada & 6 & Ireland & 1 \\
China & 5 & Italy & 1 \\
Norway & 5 & Japan & 1 \\
Cyprus & 4 & Korea & 1 \\
\hline
\end{tabular}

\section{Table 5}

The Most Productive Authors (Limited to the First 20)

\begin{tabular}{lrrr}
\hline Authors & Articles & Authors & Articles \\
\hline Evertson CM & 8 & Bradshaw CP & 3 \\
Emmer ET & 7 & Drugli MB & 3 \\
Herman KC & 7 & Freiberg HJ & 3 \\
Reinke WM & 7 & Handegard BH & 3 \\
Gold B & 6 & Jarodzka H & 3 \\
Lewis R & 5 & Leutner D & 3 \\
Holodynski M & 4 & Newcomer L & 3 \\
Kunter M & 4 & Piwowar V & 3 \\
Stormont M & 4 & Sanford JP & 3 \\
Boshuizen HPA & 3 & Thiel F & 3 \\
\hline
\end{tabular}

\section{Table 6}

Author Scientific Productivity

\begin{tabular}{lr}
\hline Number of Articles & Number of Authors \\
\hline 1 & 494 \\
2 & 45 \\
3 & 12 \\
4 & 3 \\
5 & 1 \\
6 & 1 \\
7 & 3 \\
8 & 1 \\
\hline
\end{tabular}

The most cited articles are presented in Table 7. The article authored by Brouwers and Tomic, titled "A longitudinal study of teacher burnout and perceived self-efficacy in classroom management," published in Teaching and Teacher Education in 2000, was cited 378 times and 19.89 times on average per year.
The historical direct citation network is presented in Figure 1. Emmer and Evertson were the pioneering authors as their articles have influenced several research through decades. Then, Brouwers et al. influenced the waves of research after the 2000s.

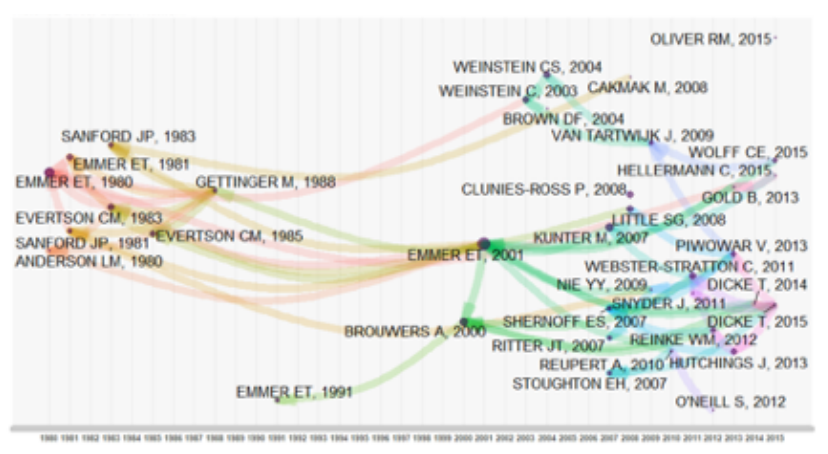

\section{Figure 1}

Historical Direct Citation Network

The annual scientific production is illustrated in Figure 2. It can also be seen in Table 1. The number of articles directly related to classroom management has increased year by year. There has been a dramatic increase after 2005. However, the number of journals in the field of education indexed by the WoS database has also increased dramatically from around 100 to over 200 after 2005. Therefore, the increase in the number of articles directly related to classroom management might be due to this change in the database.

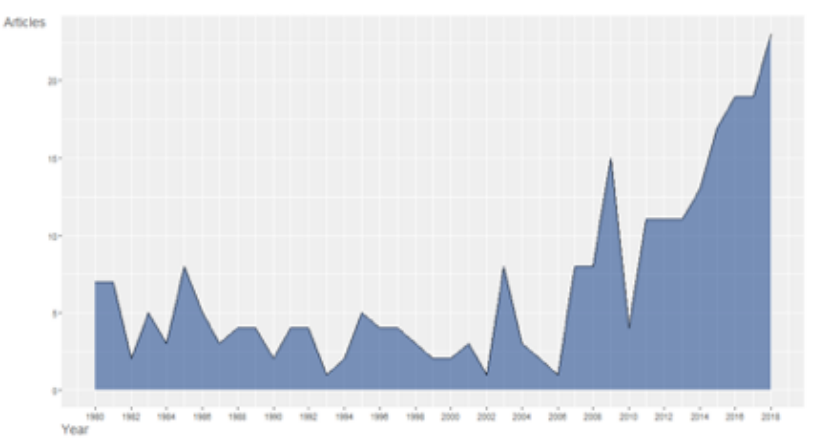

Figure 2

Annual Scientific Production

The keywords used by the authors are presented in Table 8. The most frequently used keyword was classroom management ( $n=82$ ). Based on these results, a word cloud is generated (Figure 3). 


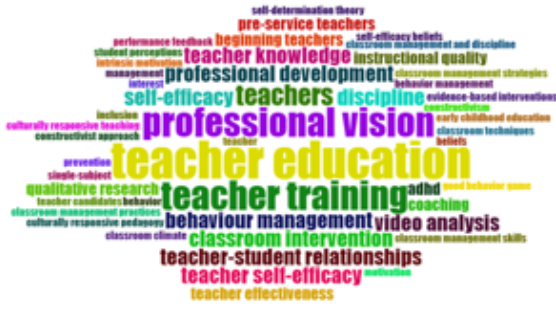

Figure 3

Word Cloud of Author Keywords (Excluding Classroom Management)

Table 9 presents the journals that published the most articles. The top three journals were Teaching and Teacher Education ( $n=25)$, Theory into Practice ( $n$ $=14)$, and Psychology in the Schools $(n=8)$. A graph representing the growth of these top three journals is presented in Figure 4. Teaching and Teacher Education had steady growth, while the growth of the other two journals were bumpy. Teaching and Teacher Education has published more articles by far after 2010.

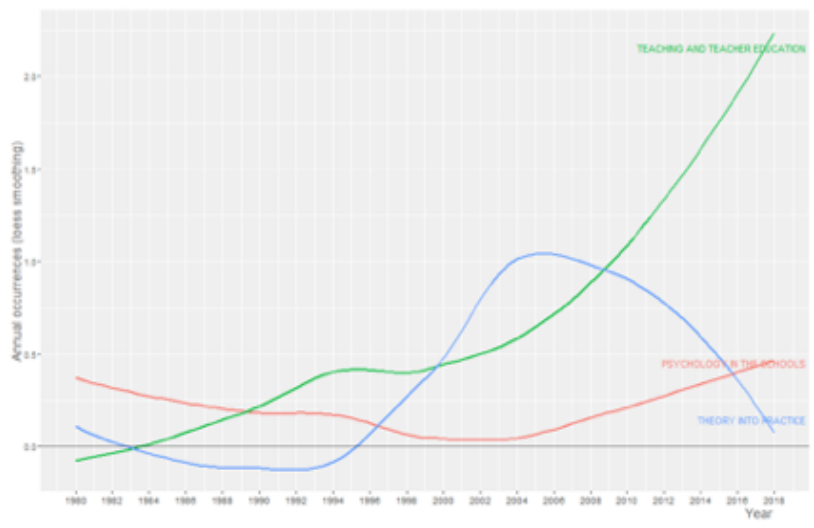

Figure 4

Growth of Top Three Journals by Year

\section{Content Analysis Results}

The content analysis of 210 articles resulted in the following three categories: method, purpose, and participants (Table 10). In the methods category, more than half of the articles $(n=119)$ employed quantitative methods, while the other most-used methods were qualitative $(n=42)$, theoretical review $(n=37)$, mixed methods $(n=8)$, and systematic review $(n=4)$. As the number of articles has increased after 2005, it makes sense that the use of these methods has also increased after 2005. However, after 2005, the use of quantitative methods has increased considerably. In the purpose category, more than half of the articles $(n=120)$ aimed to reveal either perception of research participants on different aspects of classroom management or various practices employed by the participants. Almost a quarter of the articles $(n=49)$ determined the effect of a model, intervention, or a program. The remaining 41 articles aimed to conceptualize a theory or research trend of classroom management. In the participants category, almost half of the articles ( $n=$ 103) included teachers in their samples. Students were participants in 58 research articles. Theoretical and systematic review articles $(n=43)$ had no participants. Parents, teacher candidates, supervisors, and other school stakeholders were participants in 35 studies. Finally, two articles included school administrators as research participants only. As some articles had multiple groups of participants, the total number of participant groups exceeded the number of articles.

\section{Discussion}

This study aimed to reveal trends in classroom management research through a two-stage analysis. The bibliometric analysis results identified the descriptive statistics of the articles, the most productive countries and authors, the most popular articles, journals, and keywords, annual scientific production, the growth of the top three journals by year, and the pioneer and influencer researchers in classroom management. The content analysis results showed the changes in the selection of methods, purposes, and participants for nearly three decades of classroom management research. To the best of our knowledge, so far, this is the first systematic review of all research directly related to classroom management.

The bibliometric analysis results revealed that the USA is the leading country in classroom management research. This may be because the higher education institutions in the USA than in other countries. This may also be partly because many journals indexed in the WoS database are US-based. Similar results were found in previous research (Bryman, 2007; Esen et al., 2018; Gumus et al., 2018).The content analysis results revealed that the number of quantitative studies in classroom management is greater than the number of qualitative, mixed methods, theoretical and systematic review studies. Qualitative research aims to explore the in-depth meaning of a phenomenon that is not well known. However, quantitative research aims to understand how a relatively well-known phenomenon affects a large population. As classroom management research is not in the early development stage, most researchers preferred using quantitative methods to reveal and generalize the effects of phenomena. Only a few studies employed mixed methods to research classroom management. This may be because mixed methods research is difficult to conduct, needs experience in both quantitative and qualitative methods, and requires more resources and time. The findings also revealed that articles aimed to reveal either perception of research participants on different aspects of classroom management or various practices employed by the participants 
Table 7

The 20 Articles, Which Had the Most Citations (Journal Names Are Abbreviated)

\begin{tabular}{|c|c|c|}
\hline Paper & Citations & Citations Per Year \\
\hline Brouwers A, 2000, Teaching \& Teacher Educ & 378 & 19.89 \\
\hline Emmer ET, 2001, Educ Psychol & 284 & 15.78 \\
\hline Clunies-Ross P, 2008, Educ Psychol-Uk & 143 & 13.00 \\
\hline Weinstein CS, 2004, J Teach Educ & 130 & 8.67 \\
\hline Kochenderfer-Ladd B, 2008, J School Psychol & 129 & 11.73 \\
\hline Emmer ET, 1980, Elem School J & 116 & 2.97 \\
\hline Emmer ET, 1991, Educ Psychol Meas & 107 & 3.82 \\
\hline Kunter M, 2007, Learn Instr & 101 & 8.42 \\
\hline Allen JD, 1986, Am Educ Res J & 75 & 2.27 \\
\hline Sutton RE, 2009, Theor Pract & 74 & 7.40 \\
\hline Maggin DM, 2011, J School Psychol & 70 & 8.75 \\
\hline Weinstein C, 2003, Theor Pract & 68 & 4.25 \\
\hline Bondy E, 2007, Urban Educ & 66 & 5.50 \\
\hline Marzano RJ, 2003, Educ Leadership & 62 & 3.88 \\
\hline Gencer AS, 2007, Teaching \& Teacher Educ & 60 & 5.00 \\
\hline Oliver RM, 2010, Behav Disorders & 58 & 6.44 \\
\hline Dicke T, 2014, J Educ Psychol & 57 & 11.40 \\
\hline Brown DF, 2004, Urban Educ & 57 & 3.80 \\
\hline Choi I, 2009, Etr\&D-Educ Tech Res & 56 & 5.60 \\
\hline Stoughton EH, 2007, Teaching \& Teacher Educ & 55 & 4.58 \\
\hline
\end{tabular}

outnumber the articles that determined the effect of a model, intervention, or program, and the articles tried to conceptualize a theory or research trend of classroom management. This situation has especially become prevalent after 2006. As it is easier to employ questionnaires to survey people's perceptions and practices, researchers may be more likely to opt for perceptions and practices for research purposes.

\section{Table 8}

Author Keywords (Limited to First 20)

\begin{tabular}{lcrc}
\hline Terms & $f$ & Terms & $f$ \\
\hline $\begin{array}{l}\text { classroom manage- } \\
\text { ment }\end{array}$ & 82 & $\begin{array}{r}\text { teacher-student } \\
\text { relationships }\end{array}$ & 4 \\
teacher education & 9 & teacher knowledge & 4 \\
professional vision & 7 & teacher self-efficacy & 4 \\
teacher training & 7 & video analysis & 4 \\
behavior management & 6 & adhd & 3 \\
teachers & 5 & beginning teachers & 3 \\
classroom intervention & 4 & coaching & 3 \\
discipline & 4 & instructional quality & 3 \\
professional develop- & 4 & pre-service teachers & 3 \\
ment & & qualitative research & 3 \\
self-efficacy & 4 &
\end{tabular}

This review makes an important contribution to the research on classroom management by systematically analyzing many studies indexed in the WoS database. The study results draw a big picture based on numerical evidence on the development of classroom management research. However, the study has some limitations. Although the author spent a lot of time and effort in minimizing errors during the research process, considering the nature of bibliometrics and the high number of articles, there could still be minor errors. Also, articles published in some wellknown educational journals (such as the Journal of Educational Administration, International Journal of Educational Management, School Leadership and Management, and International Journal of Leadership in Education) that were not indexed in the WoS database were excluded from the research. They were excluded because of the capabilities of the software used, and it is considered a common deficiency for systematic review studies. Future review studies may include journals excluded from this study. Finally, there may be over-generalization during the content analysis of articles. Future research should narrow the scope by focusing on a single category, such as the effect of interventions on classroom management practices and conduct a more detailed analysis of a small number of articles. 
Table 9

The Journals, Which Published the Most Articles (Limited to the First 20)

\begin{tabular}{|c|c|}
\hline Journals & Articles \\
\hline Teaching and Teacher Education & 25 \\
\hline Theory into Practice & 14 \\
\hline Psychology in the Schools & 8 \\
\hline Journal of School Psychology & 7 \\
\hline Hacettepe University Journal of Education & 6 \\
\hline Journal of Positive Behavior Interventions & 6 \\
\hline Education & 5 \\
\hline Elementary School Journal & 5 \\
\hline Journal of Education for Teaching & 5 \\
\hline Journal of Teacher Education & 5 \\
\hline Zeitschrift Fur Erziehungswissenschaft & 5 \\
\hline Education and Science & 4 \\
\hline Journal of Educational Psychology & 4 \\
\hline Phi Delta Kappan & 4 \\
\hline Urban Education & 4 \\
\hline Academic Therapy & 3 \\
\hline Behavioral Disorders & 3 \\
\hline Contemporary Educational Psychology & 3 \\
\hline Educational Leadership & 3 \\
\hline Educational Psychology & 3 \\
\hline
\end{tabular}

\section{Table 10}

The Results of the Content Analysis

\begin{tabular}{|c|c|c|c|c|c|c|c|}
\hline & Total & $91-95$ & $96-00$ & $01-05$ & $06-10$ & $11-15$ & $16-19$ \\
\hline \multicolumn{8}{|l|}{ Method } \\
\hline Quantitative & 119 & 5 & 3 & 2 & 17 & 32 & 60 \\
\hline Qualitative & 42 & 4 & 2 & 4 & 9 & 15 & 8 \\
\hline Theoretical review & 37 & 2 & 6 & 9 & 8 & 9 & 3 \\
\hline Mixed methods & 8 & 1 & 0 & 0 & 1 & 3 & 3 \\
\hline Systematic review & 4 & 0 & 1 & 0 & 0 & 2 & 1 \\
\hline \multicolumn{8}{|l|}{ Purpose } \\
\hline Perceptions and practices & 120 & 5 & 4 & 3 & 20 & 35 & 53 \\
\hline Effect of a model/intervention & 49 & 4 & 2 & 2 & 6 & 16 & 19 \\
\hline Conceptualization & 41 & 3 & 6 & 10 & 9 & 10 & 3 \\
\hline \multicolumn{8}{|l|}{ Participants } \\
\hline Teachers & 103 & 8 & 3 & 6 & 16 & 29 & 41 \\
\hline Students & 58 & 4 & 1 & 0 & 8 & 14 & 31 \\
\hline None & 43 & 2 & 7 & 9 & 8 & 11 & 4 \\
\hline Other & 35 & 0 & 2 & 1 & 9 & 13 & 12 \\
\hline Administrators & 2 & 0 & 0 & 1 & 1 & 0 & 0 \\
\hline
\end{tabular}




\section{iejee}

\section{Conclusion}

This review has proved that interest in classroom management is constantly growing. Year by year, more researchers examine perceptions on different aspects of classroom management, various practices educators employ, and the effects of new models, interventions, or programs. This implies that increasing pressures of accountability systems and high-stake testing may direct researchers to focus on improving the classroom management of teachers. As teachers' classroom management skills are crucial to making education process effective, research in this area should use quantitative methods more frequently to find ways to improve classroom management practice. However, research on classroom management is not prevalent worldwide. The issue of improving the classroom management of teachers should be independent of the pressures of accountability systems and high-stake testing, and should attract the attention of all researchers around the world.

\section{References}

Arın, E., Tunçer, B. K., \& Demir, M. K. (2016). Primary school teachers' views on constructive classroom management. International Electronic Journal of Elementary Education, 8(3), 363-378.

Aria, M., \& Cuccurullo, C. (2017). Bibliometrix: An R-tool for comprehensive science mapping analysis. Journal of Informetrics, 11(4), 959-975. doi: 10.1016/j.joi.2017.08.007

Baker, J. A., Clark, T. P., Maier, K. S., \& Viger, S. (2008). The differential influence of instructional context on the academic engagement of students with behavior problems. Teaching and Teacher Education, 24(7), 1876-1883.

Bozkus, K. (2019). Web of Science indekslerinde taranan eğitim alanındaki Türkiye kaynaklı yayınların bibliometrik analizi. Paper presented at the 14th International Congress on Educational Administration, Izmir, Turkey.

Brophy, J. E. (1996). Teaching problem students. New York, NY: The Guilford Press.

Bryman, A. (2007). Effective leadership in higher education: A literature review. Studies in Higher Education, 32(6), 693-710.

Esen, M., Bellibas, M. S., \& Gumus, S. (2018). The evolution of leadership research in higher education for two decades (1995-2014): A bibliometric and content analysis. International Journal of Leadership in Education, 1-15.
Evertson C. M., \& Weinstein, C. (2006). Classroom management as a field of inquiry. In C. M. Evertson \& C. Weinstein (Eds.), Handbook of Classroom Management: Research, practice, and contemporary issues (pp. 3-15). Mahwah, $\mathrm{NJ}$ : Lawrence Erlbaum Associates, Inc.

Greenwood, C. R., Horton, B. T., \& Utley, C. A. (2002). Academic engagement: Current perspectives on research and practice. School Psychology Review, 31(3), 328-349.

Gumus, S., Bellibas, M. S., Esen, M., \& Gumus, E. (2018). A systematic review of studies on leadership models in educational research from 1980 to 2014. Educational Management Administration \& Leadership, 46(1), 25-48.

Håkansson, J. (2015). Structured teaching and classroom management-The solution for the decline of Swedish school results? Conclusions drawn from a comparative meta-synthesis of teaching and learning. Teachers and Teaching, 21(5), 584-602.

Ihaka, R. \& Gentleman, R. (1996). R: A language for data analysis and graphics. Journal of Computational and Graphical Statistics, 5(3), 299-314.

Korpershoek, H., Harms, T., de Boer, H., van Kuijk, M., \& Doolaard, S. (2016). A meta-analysis of the effects of classroom management strategies and classroom management programs on students' academic, behavioral, emotional, and motivational outcomes. Review of Educational Research, 86(3), 643-680.

Maggin, D. M., Chafouleas, S. M., Goddard, K. M., \& Johnson, A. H. (2011). A systematic evaluation of token economies as a classroom management tool for students with challenging behavior. Journal of School Psychology, 49(5), 529-554.

Marzano, R. J., Marzano, J. S., \& Pickering, D. J. (2003). Classroom management that works: Researchbased strategies for every teacher. Virginia: ASCD.

Oliver, R. M., Wehby, J. H., \& Reschly, D. J. (2011). Teacher classroom management practices: Effects on disruptive or aggressive student behavior. Campbell Systematic Reviews, 7(1), 1-55.

Pritchard, A. (1969). Statistical bibliography or bibliometrics. Journal of Documentation, 25(4), 348-349. 
Simonsen, B., Fairbanks, S., Briesch, A., Myers, D., \& Sugai, G. (2008). Evidence-based practices in classroom management: Considerations for research to practice. Education and Treatment of Children, 31(3), 351-380.

Soodak, L. C. (2003). Classroom management in inclusive settings. Theory into Practice, 42(4), 327-333.

Stevens, K. R. (2001). Systematic reviews: the heart of evidence-based practice. AACN Advanced Critical Care, 12(4), 529-538.

Wilks, R. (1996). Classroom management in primary schools: A review of the literature. Behavior Change, 13(1), 20-32. 